\title{
An Inquiry into the Motivations of Knowledge Workers in the Japanese Financial Industry
}

(Published in the Journal of Knowledge Management, 2002, 6: 262-271)

\begin{abstract}
The knowledge base of companies is increasingly seen as underlying a firm's performance, and the role of knowledge workers within this framework is seen as strongly associated with a firm's competitive performance. This perspective views the effective management of knowledge workers as crucial in sustaining an organisation's competitive advantage. The paper views the financial industry as a knowledge intensive sector which nurtures the idea that financial firms rely on specialists' knowledge or expertise relating to a specific technical and functional domain. It is an exploratory study that aims to investigate the motivational needs of, and organisational environments best suited to, company analysts within the Japanese financial system. It identifies three key motivators as having an impact on the company analysts: monetary incentives, human resource development, and job autonomy. The paper concludes that the traditional Japanese management system is incompatible with the expectations of company analysts in the Japanese financial industry.
\end{abstract}

Descriptors: Knowledge workers, Japanese Management System (JMS), motivation, Japanese financial industry 


\section{Introduction}

Knowledge has become a prominent theme in organisation studies. There is a growing interest in the way organisations process and create knowledge. Current work has focused on organisational knowledge (Myers, 1996), knowledge-based organisations (Nonaka and Takeuchi, 1995), knowledge works (Fruin, 1997; Cutcher-Gershenfeld, 1998) and knowledge workers (Blackler, 1995; Zuboff, 1996; Drucker, 1999).

It is widely proclaimed by governments, academics, consultants and industrialists that management of knowledge is essential to competing in the 'new environment' (Tushman and Nadler, 1986). Reich (1991) argues that firms are increasingly dependent on knowledge workers as they compete through their employees' know-how. This implies that organisations must address the needs of knowledge workers in their efforts to retain their primary resource for achieving competitive advantage. However, the management of knowledge workers has only been discussed within the context of R\&D establishments, software development houses and engineering firms, labelled as 'knowledge-intensive firms' (Tampoe, 1993; Lahti and Beyerlein, 2000). In contrast, this paper emphasises the management of idiosyncratic knowledge held by knowledge workers in financial firms, rather than that held by artisans and engineers in high-tech firms. It bases its arguments on Windrum and Tomlinson's (1999) definition of firms providing financial services as knowledge-intensive firms. The authors' idea rests on the premise that financial firms, in a manner similar to high-tech firms, rely on professional knowledge or expertise relating to a specific technical or functional domain. 
Against the background of the growing significance of the KIS sectors and the input of professionals to the knowledge base of financial firms, this study sets out to explore the problems of managing company analysts in the Japanese financial market. It is commonly observed that traditional Japanese human resource management (HRM) initiatives are incompatible with the expectations of company analysts (Ide, 1999). New HRM initiatives are needed to minimise the problems of managing and motivating knowledge workers (e.g. Kuwahara, 1999). Organisational cultures that empower employees, and appeal to their inner drive, are seen as a means of overcoming some of the problems of managing knowledge workers (Kanter, 1983). This study highlights the deficiencies of the Japanese management system (JMS) in managing knowledge workers. Tampoe's (1993:55) model for managing knowledge workers serves as the theoretical schema for data analysis on the key motivators and effective work environment specific to company analysts in the Japanese business system.

\section{Managing Japanese Knowledge Workers}

Knowledge workers, in this study, represent company analysts in financial firms in the Japanese financial industry. They are defined primarily "by the work that they do, work which is relatively unstructured and organisationally contingent, and which thus reflects the changing demands of organisations more than occupationally defined norms and practices" (Scarbrough, 1999:7). Japanese company analysts' work, in general, is based on their professional knowledge about a specialised industry. They have the responsibility of researching and analysing the trends in a single industry, such as that of the automotive, telecommunications or banking. Based on general corporate and 
industrial information, company analysts formulate an analysis of the industry with each company's strengths and weaknesses and short-term and long-term profit forecasts in mind. Analysts are therefore able to provide specialist knowledge of future trends in a particular industry. This knowledge is enhanced with long periods of service in the same industry.

Today's Japanese financial industry is under greater influence from Western financial practices. New financial products are increasingly being introduced by various foreign financial institutions. For instance, currently, the largest trust fund in Japan is operated by a US subsidiary firm, Fidelity Japan. Moreover, "the industrial fund, which is the largest of its type ever seen in Japan, is being managed by Ripplewood, the US private equity group" (Tett, 1999:38). Growing merger and acquisition activity "is opening the door more fully to foreign investors and starting to encourage divestments by Japanese companies" (Lucas and Nakamoto, 1999:36). Japanese financial firms are finding it necessary to capitalise on profitable investment opportunities in the light of increasing competition in the financial sector and the rapidly ageing domestic society.

Businesses in Japan are being prompted to change their structure and management styles with the rapid liberalisation and the world-wide development of information technology. For example, new salary systems are being adopted that reward ability and accomplishment rather than longevity (The Japan Times Online, 2001). 
Although it is argued that management of specialists, in general, is difficult (e.g. Raelin, 1991; Scarbrough, 1999), that of the specialists in the Japanese financial industry, which is still preoccupied with the traditional JMS, faces even more difficulties. Conflicts between knowledge workers and company generalists in Japanese stockbroking firms are common. This has encouraged companies to reconsider the existing mechanisms available for the motivation of knowledge workers and to minimise the conflict by drawing a line of demarcation between specialists and generalists. For example, there is the creation of dual career paths for specialists and generalists in an attempt to alleviate the tension between the two groups.

The traditional JMS, based on life-time employment and seniority-based salary system (Sako and Sato, 1997), faces challenges with the 'Westernisation' of the financial industry (Hamada and Horiuchi, 1999). There is a call for Japanese stockbroking firms, competing with Western companies, to change their reward and employment systems to match those of the West with respect to the management of company analysts (Shimizu, 1999).

At this stage, it is helpful to set out what we mean by the JMS model. The JMS, which still has a strong foothold in Japan, is composed of the elements observed in Table I.

Take in Table I 
The JMS is regarded as a system based on internal promotion and training, unclear job descriptions, with employees possessing a relatively strong sense of job responsibility and commitment to work. The life-time employment practice is seen as conducive to the effective implementation of these sub-systems. In contrast to the Japanese model, it is commonly observed that in Western organisations, which are seen as following Taylorist principles (Whitley, 1999), there are rigid job routines, specialisation, functional management and rigorous selection (e.g. Warner 1994).

There is a growing concern in the Japanese financial industry over whether the traditional JMS model, which is still heavily used in the automotive industry (Liker et al, 1999), is applicable to the effective management of knowledge workers in the financial sector (Kuramoto, 1998; Saga, 1998). The present research indicates that a 'pure' form of JMS does not meet the expectations of such workers. The JMS model is suitable for establishing and managing a group of generalists under a life-time employment system. It provides rewards in the form of seniority pay and pension. This is complemented by the internal employee training system, which increases the retention rate of employees. However, specialists are increasing in number and importance in the financial industry. They require specific rewards in the form of high salaries and merit-based promotion in a relatively short period, within an environment that allows for relatively easy transfer to the Western financial firms. Japanese financial firms' traditional HRM system is being challenged by the increasing number of company analysts transferring to firms that can offer better incentives. In addition, Japanese company analysts are exposed to Western analysts' behaviour and value systems on their visits to overseas customers, and in their 
regular interactions through meetings and information transfer between the Tokyo subsidiary and the US or European headquarters. Such exposure to Western analysts' practices is increasingly having an influence on Japanese analysts' perceptions of organisational practices.

The following sections in the paper outline the factors that have an impact on the knowledge workers' motivation in the Japanese financial market. In the first section, the research method is described. The second section presents the research findings, where factors that are critical in discerning the compatibility of the JMS with the expectations of knowledge workers are discussed. The final section presents the conclusions and the implications for effective work environments.

\section{Research Methods}

This paper is based on an ethnographic study that focuses on the key factors that motivate knowledge workers in the Japanese financial industry. The interest was in examining the social relations and processes surrounding knowledge workers rather than identifying discrete taxonomies of knowledge-working systems. An ethnographic research methodology made it possible for the insider to capture, understand and analyse social relations, social processes and methods of management support (Hammersley and Atkinson, 1995). In other words, a process-based account enabled the researcher to understand the situational logic, and the impact of conditions in the financial industry, directly related to the knowledge working system. 
Half the body of information was drawn from structured interviews, whilst the other half was drawn from the primary researcher's own on-site observations during her employment as a company analyst in a securities company from April 1988 to July 1993. She then transferred to a Japanese bank's subsidiary to work in the asset management field from September 1993 to July 1997. The main fieldwork was conducted in the Tokyo financial market. Given Japanese financial institutions' strong emphasis on the importance of confidentiality, the researcher was obliged to immerse herself in the social, political, and technical aspects of the financial industry's operations and activities through an employment contract.

Structured telephone interviews with six company analysts were conducted to enrich and verify the ethnographic data. The unit of analysis, in this context, was a group of specialists with 10 or more years service in the Japanese financial industry as salaried, full-time specialists, aged between mid-30 and 40, using the same methods to analyse the industry, and with similar skills levels. Our main line inquiry was the broad swathe of organisations which, to some degree and in at least some quarters, had been affected by the liberalisation of the Japanese financial market. The sampled firms included Tokyo branches of a small-sized Japanese stockbroking firm, a large Japanese stockbroking firm, two large US stockbroking firms, a medium-sized Japanese stockbroking firm and a large US investment bank, all with an employment preference for local staffing.

Each interview lasted on average somewhere between one and a half and two hours. Interview questions focused on the interviewees' role within the organisation, their work 
history including a transfer decision to another firm and the reasons underlying this decision, their understanding of what constituted an effective work environment, and which organisational factors hindered and facilitated their intention to change companies. Three of the interviewees had taken the decision to transfer to US financial firms. The remaining three worked for a Japanese stockbroking firm.

Before considering the results, the scope and limitations of this study should be noted. The firms discussed here are not necessarily representative of all firms operating in Japan. Some of the cases are well-known internationally-leading companies. The others, as mentioned earlier, have taken steps to accommodate for the 'Westernisation' of the Japanese financial industry by questioning the applicability of the Japanese management system in the light of an industry in transition. In broad terms, the sample was designed to reflect the middle band of major organisations operating in the Japanese financial industry which are facing growing concern over the effectiveness of the JMS model in the management of knowledge workers.

Another limitation of this paper is that it reports on work-in-progress. In relation to this point, the scope of this paper does not provide an inclusive coverage of the various themes which the work experience of the primary researcher addressed. For example, we do not report here on the comparative study of the JMS with the Western management model and the nature of the transformation of the JMS model. Rather, the aim of this paper is to focus on a set of organisations that are faced with competing models of how to 
manage knowledge workers and require a shift in behaviours in order to meet this challenge.

\section{Research Findings}

Research findings reveal information on the motivators that are relevant for the effective management of knowledge workers in the Japanese financial context. The present study identifies three major reasons for company analysts' choice in seeking positions in other financial firms. These are concerns over monetary incentives, human resource development practices (that is promotional opportunities and job rotation) and job autonomy. These were expressed by an interviewee as: "In general, there are three reasons company analysts decide to change a company: payment, conflict with management, and the offer of a higher position" (CA2 from a Japanese stockbroking firm [2]). The most widely cited reason for a transfer decision is perceived as unfair treatment. Company analysts seek considerable personal job satisfaction. This is seen by the research participants as closely associated with high salary and status.

The following sub-sections detail the three key motivators: monetary incentives, human resource development and job autonomy. Tampoe's (1993) model is used as a theoretical backbone for contextualising the factors that motivate knowledge workers (see Figure 1).

Take in Figure 1 
Although other theories relating to motivation, such as the expectancy model by Porter and Lawler (1968), are well established, they do not discuss motivation-related concepts within the context of managing knowledge workers. The relevance of Tampoe's work rests on the notion that the resulting implications of the model for the management of knowledge workers are relatively clearer. Since firms increasingly compete through their know-how, they are increasingly becoming dependent on the workers who supply such know-how (Reich, 1991). "Organisations must therefore cater for the special needs and operations of this group if they are to successfully exploit their skills and to retain their primary source of competitive advantage" (Scarbrough et al., 1998:10). Tampoe's model shows how this involves changes in the structure, culture and management style employed within organisations. It is claimed that knowledge workers can be carefully integrated within a supportive work environment through carefully engineered work culture (Raelin, 1991). For instance, high-tech firms avoid the form of bureaucracy that is designed for the purpose of control, for management's desire for control over many key operating decisions and many symbolic differences between workers and managers can reinforce an adversarial workplace whereby management-employee relations are restrained (McMillan, 1996). Corporate culture can help instil commitment to corporate goals without the need for an elaborate organisational structure whereby knowledge workers can derive social benefits from the prevailing culture (Scarbrough et al., 1998).

Tampoe (1993:51) argues that the following motivators interact to yield motivated behaviour: 
i. Money - earning an income which is a just reward for the contribution made enables employees to share in the wealth they create, through incentive schemes geared to their company's success but related to their personal performance.

ii. Personal growth - the opportunity for individuals to realise their potential, supporting the hypothesis that knowledge workers [are] seeking intellectual, personal and career growth.

iii. Task achievement - the achievement of producing work to a standard and quality of which the individual can be proud. There is a need for the task undertaken to be relevant to the organisation.

iv. Operational Autonomy - a work environment in which knowledge workers can achieve the tasks assigned to them within the constraints of strategic direction and self-measurement indices.

The present study illustrates that the fourth element in Tampoe's model—operational autonomy-is not observed among the company analysts in practice, because knowledge workers in the Japanese financial industry are not simply assigned tasks within the constraints of strategic direction and self-measurement indices. They are expected to work closely with others in a team effort, such as with team members who have expertise on mergers and acquisitions (M\&A), corporate finance or sales. The global operations of financial firms appeal to company analysts' personal growth needs. For instance, CA6, from a US stockbroking firm, has chosen to transfer because: “This company has a global network, so that we can handle larger deals such as mega-mergers like that of Nissan and Renault". Similarly, CA5, from a US investment bank, claims that: "This company has 
better sales forces to deal with overseas customers than what my previous company had. Good sales and good research need to be together; that creates company competitiveness".

The following sections discuss the empirical findings with regard to the first three motivators—-money, personal growth and task achievement—in Tampoe's model.

\section{Monetary Incentives}

Salary is identified as a major factor in the transfer decision of company analysts. This is reflective of company analysts' perception of their American counterparts: "Behind the great strength of American financial institutions lies the motto, 'work hard, have fun, get paid well"' (Kuwahara, 1999:4). The perception of salary as a major factor in analysts' transfer decision is partly due to the fear of losing jobs. It is felt that jobs are not secure, because there is the risk of foreign companies withdrawing their operations from Tokyo upon encountering financial difficulty. For example, when Barclays De Zuet Wedd withdrew from the equity business in Tokyo upon a strategic decision made by the London headquarters, the Tokyo branch faced job losses. The branch did not have the power to reverse the decision. CA3, from a US stockbroking firm, emphasises the job insecurity aspect in his transfer decision: "I thought that this company would never withdraw from Tokyo. I need a certain degree of job stability. This is one of the reasons why I chose to join this company [that is the US stockbroking firm]".

In addition, company analysts consider fairness as having an impact on their motivations to stay at a given firm. High salaries earned by top company analysts-individuals who 
have attained a good reputation in the company and can easily attract customers-in the Japanese financial industry create a sense of dissatisfaction with the reward system in firms that employ the JMS model. Although there is a desire to earn higher salaries, there is no opportunity to receive large pay rises in traditional Japanese firms. The salary differential within the JMS model is kept minimal in order to sustain fairness in reward distribution (Sato 1997). If company analysts choose to cease their membership with the JMS model by leaving their 'traditional' firms, they will no longer be entitled to a high level of retirement pay. This is seen as a disincentive by the analysts.

Company analysts are also motivated by the opportunity to negotiate payment terms and compensations for company-related expenses. For example, CA3, from a US stockbroking firm, sees the negotiation process as an entertainment: "Our job is really hard and time-consuming. Even having long holidays is difficult. Under these circumstances, yearly payment negotiation is the one and only entertainment and reward for me". Given their strong external social networking practices, analysts are often aware of the allowance systems each company offers to its employees. This is exemplified by CA2's (from a Japanese stockbroking firm) account: "If we miss the last train due to report-writing, we have to pay the taxi fare ourselves. But I heard that some companies compensate their employees for that expense, because they see it as a necessary cost. These small things generate a feeling of unfairness". Once analysts become aware of an 'inequitable' compensation system, they initially attempt to change the system in their own companies. If they cannot achieve any results in their attempts to initiate a change, then they choose to transfer to other companies. 
Consequently, high monetary reward, or incentive schemes geared to company success and related to analysts' individual performance, is identified as a significant motivator for analysts' commitment to achieving company goals.

\section{Human Resource Development}

Research results reveal that internal promotion and job rotation, which are essential constituents of the JMS model (Sako and Sato 1997; Iida, 1998), have a significant impact on the motivation of knowledge workers.

An internal promotion system constrains company analysts' opportunity to be promoted to higher ranks in the firm. In general, there are openings for a single senior and a single junior analyst of each industry in the Japanese financial sector. Under the current JMS model, a junior analyst cannot become a senior analyst if a senior analyst already exists in a research team that is responsible for analysing a particular industry. This situation holds true regardless of the junior analyst's achievements. It generates a feeling of unfair treatment among junior analysts. This observation is supported by CA2 from a Japanese stockbroking firm: "Some analysts transferred their companies, because higher positions were limited and they had no chance of being promoted".

By the same token, job rotation creates dissatisfaction among the analysts, as the system is seen as inhibiting the process of building expertise. Under the JMS model, core employees are 'ordered' to move to other departments, upon a perceived need, by 
management. Company analysts, in general, do not have the desire to become generalists. The nature of their task requires specialism. This necessitates a vertical rather than a horizontal move up the organisational hierarchy. The voice of company analysts, like that of consultants, has become louder as they have increasingly come to be recognised as knowledge workers. An exception to this rule is the female population. As female company analysts are not subjected to job rotation, they can continue reaping the benefits associated with a specialist's position. However, this also means that they will not benefit from a promotion opportunity, as they are not given the chance to acquire generalist skills through the job rotation system.

In addition to the impact that job rotation has on individual skill development, there is the issue of a team's dispersion upon the transfer of a team member to another department. Company analysts are aware of the fact that they are valued by management as long as they operate in a team along a project-based structure. This is substantiated by CA6 from a US stockbroking firm: "I was depressed when my colleague moved due to job rotation. To me, it meant that I had to build up a new team".

Consequently, the JMS model, which nurtures internal promotion and job rotation, does not provide for the needs of company analysts from a human resource development point of view. Company analysts prefer to seek intellectual and personal opportunities for career advancement. 


\section{Job Autonomy}

Research findings indicate that company analysts require considerable autonomy to carry out their tasks. This is in line with the arguments in the literature that "knowledge workers enjoy greater power and autonomy at the workplace because their expertise is both more difficult to control and more marketable to other employees" (Scarbrough et al., 1998:12). Company analysts regard their product-specific knowledge as constituting competitive advantage. They have the ambition to constantly acquire new knowledge. Company analysts are trained to be assertive through learning by doing (Lave \& Wenger, 1991). They start interviewing senior managers at a junior analyst position, that is they: "...carry out business with top managers from the start of their career" (CA6 from a US stockbroking firm). They do not appreciate being assigned administrative tasks and see such assignments as 'irresponsible' behaviour on the part of the managers. CA2, from a Japanese stockbroking firm, argues: "Managers should reject unnecessary [such as administrative] tasks from other departments, and avoid asking analysts to carry them out. Some managers simply cannot do that". This suggests that company analysts require freedom to pursue their profession without divergence from their areas of specialism.

Furthermore, company analysts do not want to be drawn into departmental conflict. They feel that they already have the conflicting requirements of primary and secondary markets to deal with. For example, if a company analyst is in charge of a retail sector, such as TESCO, and is working to issue new equity for TESCO with his/her primary market team members, he/she is prohibited from disclosing 'insider' information to the secondary market team members who are in charge of serving the institutional investors. 
It is claimed that management does not understand the conflicts ingrained in analysts' work. For example, conflict between equity issuers, investors and management is common. If an analyst makes a negative profit forecast for a large institutional investor and incorrectly recommends the sale of that company's stocks, then the analyst runs the risk of losing his/her business contract with the stockbroking firm. Customers can also sanction the disclosure of business-related information to the analyst. If the company analyst remains silent, he/she will be breaking the 'prudent-man rule', which requires all employees in the investment management field to act in the best interests of the final investors (Aoki and Patrick, 1994). The autonomy that company analysts enjoy over the process by which they exercise their knowledge has implications on the responsibility they assume. They are held accountable for their actions.

Company analysts are recognised by their individual work rather than by the reputation of the firm with which they are affiliated (CA5 from a US investment bank). In spite of the large workload and the risk involved, company analysts commonly cite a considerable degree of freedom and flexibility as necessary for their work. The incompatibility between management's expectation of analysts' work responsibility and the analysts' need for autonomy discourages trust formation between company analysts and management [3]. This, in turn, hinders the development of a cultural condition of adherence to common norms, a web of obligations and expectations and identification with the community necessary for knowledge absorption (Nahapiet and Ghoshal, 1998). 


\section{Conclusion}

The present research shows that there are three major factors that have an impact on Japanese knowledge workers', that is company analysts', motivation to be committed to working at the same financial firm for a long span of time. These are: monetary incentives, human resource development or personal growth, and job autonomy or task achievement.

Tampoe's (1993) research on motivating knowledge workers offers guidance to managers on motivators and management methods appropriate in deriving high performance from knowledge workers. Research findings reveal that there is a need for Japanese managers to be aware of company analysts' desire to realise their potential, achieve work of a high standard and earn an income that is seen as a reward for personal contribution. According to Tampoe (1993), this will enable employees to share in the wealth created by them. As Capelli and Singh (1992) contend, promotion systems which lock-in high performers can aid in retaining the knowledge of company analysts.

The JMS model does not cater for the motivational needs of company analysts. Internal promotion and job sharing, equity in salary distribution, low job autonomy are not regarded as conducive to the motivation of knowledge workers and, in turn, retaining their knowledge. Knowledge workers require a supporting environment in which they are given high levels of operational autonomy to carry out their tasks. In the JMS model, employees are often treated in a paternalistic manner. It is commonly seen that, "the feeling of identification with the company is important for the employees" (Iida, 
1998:334). However, this does not necessarily apply to company analysts. There is an important difference between knowledge workers and other employees in financial firms in terms of the conditions required to combine the mastery of some highly specialised technical expertise with the ability to work effectively in teams. Company analysts frequently transfer to firms that offer more creative autonomy, as related to task achievement, than organisational autonomy, as related to managerial authority, to make decisions [4] where they can exercise more control over the mobilisation of organisational resources to implement their ideas. They maintain external networks with other analysts in the financial industry and transfer to jobs that are similar in terms of profit forecasts and code of conduct, but different in terms of research aims, when the need arises. They prefer to identify themselves as company analysts rather than as members of a securities company. The degree of autonomy required by company analysts is in contradiction with management's desire for control (Raelin, 1991). As far as this study is concerned, knowledge workers do not like working under close supervision and direct control.

This research gives pointers to the nature of the work environment that can be effective in motivating knowledge workers in the Japanese financial industry. The commercial relevance of the job, defined by Tampoe (1993:54) as "the need for the assigned task to be relevant and important to the business", the freedom to pursue the job [defined as creative autonomy] and resources, both in terms of salary and support systems to carry out tasks, are essential for an effective work environment. 
"It must be remembered that the specialists' post-system has features that are hard to combine with Japanese type organisations since under the Japanese-style management system, rotation is eventually necessary because of the permanence of relations within organisations" (Iwata:1982:53). Given Iwata's argument on the difficulty of integrating the JMS model into the management system of the West, managers need to be aware of the trade-offs evident in running both systems in parallel. For instance, there are problems inherent in having two systems where generalists are developed through job rotation for the creation of firm-specific knowledge, and specialists are trained on-the-job for the creation of product-specific knowledge.

Although the JMS model has the merit of developing generalists through a job rotation system, life-time employment and seniority-based pay, it has the de-merit of imparting to employees unfocused, broad knowledge. Generalists may be familiar with their company's strengths and weaknesses, but they may not necessarily have in-depth knowledge that specialists, or company analysts, may possess in particular areas. The difference in the nature of knowledge acquired by both groups - the specialists and the generalists - may result in misunderstandings and underestimation of each other's work. For instance, Scarbrough (1999) points out the common misconception that 'playermanagers', who are basically company analysts occupying managerial positions, can manage junior analysts effectively. However, as Raelin (1991) purports it is important to have a 'professional administrator' to manage professionals. 
It is not the aim of this paper to suggest a meta-theory of knowledge worker motivation. All companies should aim to adopt a model that is suited to their local context. At the same time, it is beneficial to be aware of the alternative models with which other companies are working. For example, current research on European firms suggests that "firms are simultaneously building hierarchies and networks, seeking greater performance accountability upward, and greater horizontal integration sideways, and attempting to centralise strategy and decentralise operations" (Pettigrew, 1999:5). This research highlights the importance of both horizontal and vertical structures in the management of employees. In other words, companies need to match their strategies with operations in order to achieve the targeted outcome. In this sense, reducing the size of the core workforce composed of the generalists, and creating a dual career path to accommodate the specialists, can prove fruitful in sustaining high levels of generalist and specialist motivation. There are examples of companies, such as the Daiwa Securities, Nikko Solomon Smith Barney Securities, which have shifted their systems to accommodate the needs of both core employees and knowledge workers. They have incorporated vertical hierarchical systems for generalists and additional career paths for specialists.

\section{References}

Aoki, M. and Patrick, H. (1994), The Japanese Main Bank System: Its Relevance for Developing and Transforming Economies, Oxford University Press, New York.

Blackler, F. (1995), "Knowledge, knowledge work and organisations: an overview and interpretation”, Organisation Studies, Vol. 16, No. 6, pp. 1021-46. 
Capelli, P. and Singh, H. (1992), "Integrating strategic human resources and strategic management", in Lewis, D., Mitchell, O. S. and Sherer, P. D. (Eds), Research Frontiers in Industrial Relations and Human Resources, Industrial Relations Research Association, University of Wisconsin, Madison, pp. 165-92.

Cutcher-Gershenfeld, J., Nitta, M., Barret, B. J., Belhedi, N., Chow, S. S., Inaba, T., Ishino, I., Lin, W., Moore, M. L., Mothersell, W. M., Palthe, J., Ramanand, S., Strolle, M. E. and Wheaton, A. C. (1998). Knowledge-driven Work: Unexpected Lessons from Japanese and United States Work Practices, Japan Business and Economic Series, Oxford University Press, New York.

Drucker, P. (1999), "Knowledge-worker productivity: the biggest challenge", California Management Review, Vol. 41, No. 2, pp. 79-94.

Fruin, W. M. (1997), Knowledge Works: Managing Intellectual Capital at Toshiba, Oxford University Press, Oxford.

Hamada, K. and Horiuchi, A. (1999). "The political economy of the financial market”, in Tsutsui, W. M. (Ed), Vol. 3, Banking in Japan, Routledge, London, pp. 30-68.

Hammersley, M. and Atkinson, S. (1995), Ethnography: Principles in Practice, $2^{\text {nd }}$ ed., Routledge, London.

Ide, S. (Ed) (1999), "Developing a sound asset management industry in Japan", Security Analysts Journal, Vol. 37, No. 1, pp. 3-11.

Iida, F. (1998), Nihonteki Keiei no Ronten (The Points of Japanese Management System), PHP Shinsho, Tokyo.

Iwata, R. (1982), Japanese-Style Management: Its Foundation and Prospects, Asian Productivity Organisation, Tokyo. 
The Japan Times Online (2001), "U.S. power reforms, IT sarking change in Japanese industries", 21 March, http://www.japantimes.co.jp/cgi-bin/getarticle.p15?nb20010321a7.htm.

Kanter, R. M. (1983), The Changemasters, George Allen and Unwin. London.

Kuramoto, Y. (1998), "Managing investment professionals: research analysts", Security Analysts Journal, Vol. 36, No. 6, pp. 14-28.

Kuwahara, M. (1999), “Can American finance become global standard?”, Management Japan, Vol. 32, pp. 2-7.

Lahti, R. K. and Beyerlein, M. M. (2000), "Knowledge transfer and management consulting: a look at the firm", Business Horizons, Vol. 43, No. 1, pp. 65-74.

Lave, J. and Wenger, E. (1991), Situated Learning: Legitimate Peripheral Participation, Cambridge University Press, Cambridge.

Liker, J. K., Fruin, W. M. and Adler, P. S. (1999), Remade in America: Transplanting and Transforming Japanese Management Systems, Oxford University Press New York.

Lucas, C. and Nakamoto, N. (1999), "Japan banks fight for local M\&A deals", Financial Times, 30 November, pp. 36.

McMillan, C. J. (1996), The Japanese Industrial System, $3^{\text {rd }}$ ed., Walter de Gruyter, Berlin.

Myers, P. S. (1996), Knowledge Management and Organisational Design, Butterworth-Heinemann, Boston. 
Nahapiet, J. and Ghoshal, S. (1998), "Social capital, intellectual capital and the organisational advantage", Academy of Management Review, Vol. 23, No. 2, pp. 24266.

Nonaka, I. and Takeuchi, H. (1995), The Knowledge-creating Company: How Japanese Companies Create the Dynamics of Innovation, Oxford University Press, New York.

Pettigrew, A. (1999), “Organising to improve company performance”, Hot Topics, Vol. 1, No. 5, Warwick Business School, University of Warwick, Coventry, U.K.

Porter, L. W. and Lawler, E. E. (1968), Managerial Attitudes and Performance, R. D. Irwin, Homewood, Illinois.

Raelin, J. (1991), The Clash of Cultures: Managers Managing Professionals, Harvard Business School Press, Boston.

Reich, R. (1991), The Wealth of Nations: Preparing Ourselves for $21^{\text {st }}$ Century Capitalism, Simon and Schuster, London.

Saga, T. (1998), Merrill Lynch no sinjitsu (The truth about Merrill Lynch), Nihon Tanpa hoso, Tokyo.

Sako, M. and Sato, H. (1997), Japanese Labour and Management in Transition, Routledge, London.

Sato, H. (1997), "Human resource management systems in large firms", in Sako, M. and Sato, H. (Eds), Japanese Labour and Management in Transition, Routledge, London, pp. $104-30$. 
Scarbrough, H. (1999), "Knowledge as work: conflicts in the management of knowledge workers", Technology Analysis and Strategic Management, Vol. 11, No. 1, pp. 5-16.

Scarbrough, H., Swan, J. and Preston, J. (1998), Knowledge Management and the Learning Organisation: The IPD Report, Institute of Personnel Development, London.

Shimizu, Y. (1999), "Incentive system no sekkei (Designing the incentive system)", in Research Committee of Capital Markets (Ed.), Shoken Keiei no Frontier (The frontier of stockbrokers' management), Seibun sha, Tokyo, pp. 193-236.

Tampoe, M. (1993), "Motivating knowledge workers - the challenge for the 1990s", Long Range Planning, Vol. 26, No. 3, pp. 49-55.

Tett, G. (1999), "Equity funds to buy industrial companies", Financial Times, 18 November, pp. 38.

Tushman, M. and Nadler, D. (1986), "Organising for innovation", California Management Review, Vol. 28, No. 3, pp. 74-88.

Warner, M. (1994), "Japanese culture, Western management: Taylorism and human resources in Japan", Organisation Studies, Vol. 15, No. 4, pp. 509-33.

Whitley, R. (1999), Divergent Capitalisms: The Social Structuring and Change of Business Systems, Oxford University Press, Oxford.

Windrum, P. and Tomlinson, M. (1999), "Knowledge-intensive services and international competitiveness: a four case comparison", Technology Analysis and Strategic Management, Vol. 11, No. 3, pp. 391-408. 
Zuboff, S. (1996), "The abstraction of industrial work”, In Myers, P. S. (Ed), Knowledge Management and Organisational Design, Butterworth-Heinemann, Boston, pp. 197207.

Table I. Analytical Perspective on the Comparison of Western and Japanese Management Models [1]

\begin{tabular}{|l|l|l|l|}
\hline $\begin{array}{l}\text { Characteristics } \\
\text { of Management } \\
\text { Model }\end{array}$ & Descriptors & West & Japan \\
\hline HR Practices & Promotion & External & Internal \\
\cline { 2 - 4 } & Job description & Clear & Unclear \\
\cline { 2 - 3 } &
\end{tabular}




\begin{tabular}{|l|l|l|l|} 
& $\begin{array}{l}\text { Training or } \\
\text { Skill upgrading }\end{array}$ & Through job transfer & $\begin{array}{l}\text { Internal, paternalistic } \\
\text { (Compulsory and } \\
\text { long-term) }\end{array}$ \\
\cline { 2 - 4 } & $\begin{array}{l}\text { Promotion } \\
\text { Reward system }\end{array}$ & $\begin{array}{l}\text { Job transfer } \\
\text { (based on rational ability) }\end{array}$ & $\begin{array}{l}\text { Internal } \\
\text { (based on one's effort, } \\
\text { 'competence trust') }\end{array}$ \\
\hline Human relations & Communication & $\begin{array}{l}\text { Importance of } \\
\text { individualism }\end{array}$ & $\begin{array}{l}\text { Importance of } \\
\text { harmony/collectivism }\end{array}$ \\
\hline Basic values & View of life & $\begin{array}{l}\text { Seeking material } \\
\text { success }\end{array}$ & $\begin{array}{l}\text { Seeking emotional/ } \\
\text { psychological success }\end{array}$ \\
\hline Attitude to work & $\begin{array}{l}\text { Sense of job } \\
\text { responsibility }\end{array}$ & Low & Strong \\
\cline { 2 - 4 } & Commitment to & Individual task & Firm \\
\hline
\end{tabular}

Source: Iida (1998:140-141) 
Figure 1. Model for Motivating Knowledge Workers

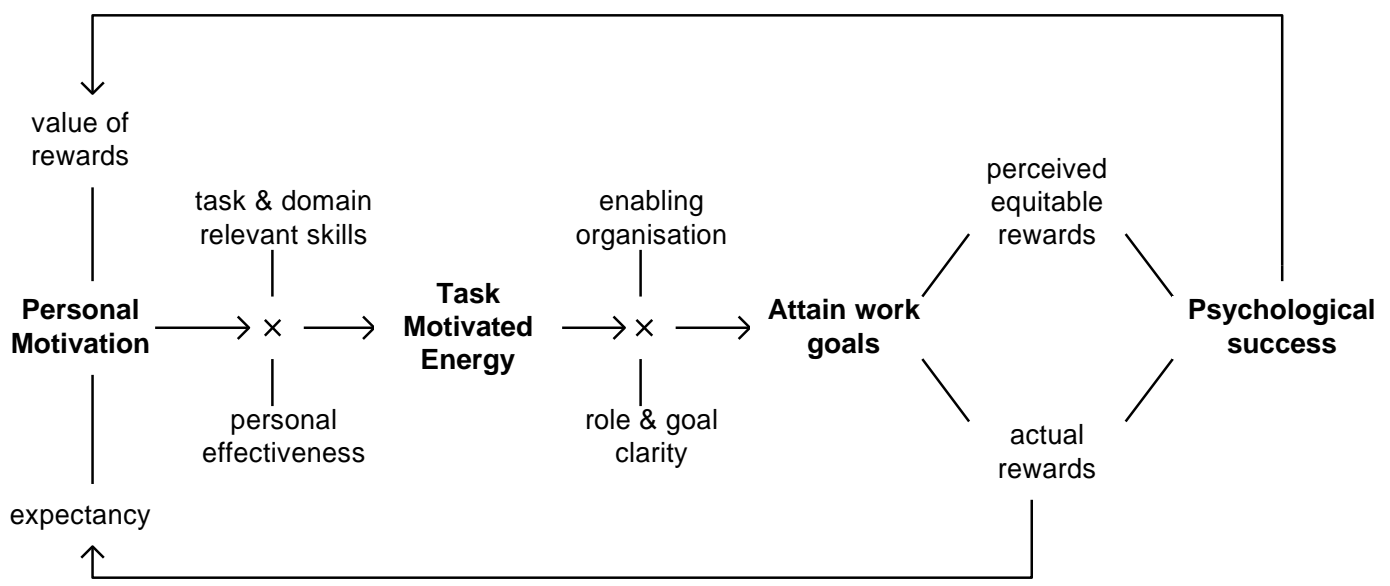

Source: Tampoe (1993:55) 


\section{Notes}

1. The factors listed in this table should not be taken as binary opposites. The table provides a theoretical distinction based on relativism rather than absolutism.

2. Please note that all names in the article have been changed to ensure anonymity.

3. This is closely associated with analysts' perception of unfair treatment discussed in the section on Monetary Incentives.

4. According to Raelin (1991:19), creative autonomy refers to autonomy over processes, that is "freedom to examine problems using the methods in which one has been trained", whilst organisational autonomy refers to autonomy over setting of tasks that salaried employees work to achieve in organisations. 